\title{
NARRATIVAS DIGIFEMINISTAS: ARTE, ATIVISMO E POSICIONAMENTOS POLÍTICOS NA INTERNET
}

\author{
CARLA DE ABREU \\ Universidade Federal de Goiás
}

RESUMO A forte incorporação das tecnologias nas práticas cotidianas realimentou as relações de poder e os discursos hegemônicos nos ambientes digitais, no entanto, também favoreceu a visibilização de correntes feministas críticas e questionadoras dos discursos dominantes e sexistas. Neste artigo, reviso o contexto do ciberfeminismo, um movimento que surgiu na década de 1990 e influenciou uma nova geração que hoje se empenha na construção de uma internet feminista e combativa. Os subsídios partem de uma pesquisa na qual analiso as práticas de subjetividade das identidades nas redes sociais, em que as ações feministas formam parte das reflexões e do marco teórico. A abordagem metodológica é a netnografia e a análise de conteúdo. 0 termo digifeminista é usado para pensar as ações políticas e as produções artísticas de jovens mulheres que, de maneira similar às ciberfeministas do passado, usam as ferramentas digitais para expressar opiniões e executar estratégias de oposição às hegemonias e opressões nos ambientes digitais. Apresento também algumas artistas digifeministas que exploram novos significados do corpo feminino, expressando feminilidades alternativas que escapam, interpelam e testam os limites das políticas da sexualidade contemporânea, com o objetivo de apontar o que as normas excluem, inviabilizam ou silenciam.

Palavras-chave: Digifeministas. Internet. Ativismo. Arte digital.

\section{ABSTRACT DIGIFEMINIST NARRATIVES: ART, ACTIVISM AND POLITICAL POSITIONING IN THE INTERNET}

The strong incorporation of technologies in the daily practices has renourished the relation of power and the hegemonic discourses in the digital environment; however, it has also favored the visibility of critical and questioning feminist currents of the dominant and sexist discourses. In this paper I revise the context of Cyberfeminism, a movement that emerged in the 1990's and has influenced a generation that nowadays endeavors in the construction of a feminist and 
combative internet. The subsides come from a research in which I analyze the subjective practices of the identities in social medias, where the feminist actions form a part of the reflection and of the theoretical framework. The methodological approach is the netnography and the analysis of content. The term digifeminist is used to think the political actions and artistic productions of young women who, in a similar way to the digifeminists of the past, use the digital tools to express opinions and to execute strategies of opposition to the hegemonies and oppressions of the digital environment. I also present some digifeminist artists that explore new meanings of the female body, expressing alternative femininities that escape, interpellate and test the limits of the contemporary politics of sexuality, with the objective of pointing towards what the norms exclude, derail or mute.

Keywords: Digifeminists. Internet. Activism. Digital art.

\section{RESUMEN}

\section{NARRATIVAS DIGIFEMINISTAS: ARTE, ACTIVISMO Y POSICIONAMIENTOS POLITICOS EN INTERNET}

La fuerte incorporación de la tecnología en las prácticas cotidianas realimentó las relaciones de poder y los discursos hegemónicos en los entornos digitales, sin embargo, también favoreció la visibilización de corrientes feministas críticas y cuestionadoras de los discursos dominantes y sexistas. En este artículo revisé el contexto del ciberfeminismo, un movimiento que surgió en los años 90 e influyó una nueva generación que hoy en día se dedica a la construcción de un internet feminista y combativo. Los subsidios se basan en una encuesta en la que analizo las prácticas de subjetividades de las identidades en las redes sociales, donde las acciones feministas forman parte de las reflexiones y del marco teórico. El enfoque metodológico es la netnografía y el análisis de contenido. El término digifeminista se utiliza para pensar las acciones políticas y las producciones artísticas de jóvenes mujeres que, de manera similar a las ciberfeministas del pasado, utilizan las herramientas digitales para expresar opiniones y ejecutar estrategias de oposición a las hegemonías y opresiones en los entornos digitales. También presento algunas artistas digifeministas que exploran nuevos significados del cuerpo femenino, expresando feminidades alternativas que escapan, interpelan y prueban los límites de las políticas de la sexualidad contemporánea, con el fin de señalar lo que las reglas excluyen, inviabilizan o silencian.

Palabras clave: Digifeministas. Internet. Activismo. Arte digital. 
Grande parte dos estudos acadêmicos sobre as ciberculturas ou a influência das tecnologias nas sociedades contemporâneas introduz os textos argumentando, não sem razão, sobre as transformações nas formas como compreendemos o mundo após o surgimento da internet. Sem querer ser redundante, o fato é que, em menos de duas décadas, vivenciamos uma série de mudanças, após a forte incorporação dos artefatos digitais nas práticas cotidianas, colaborando, inclusive, para a hibridização dos contextos on-line e off-line, não sendo mais possível uma separação ontológica dessas duas dimensões.

Essas mudanças podem ser observadas nas formas como alteramos a compreensão de alguns conceitos importantes como tempo e lugar, exibição e intimidade, público e privado. Apesar de ser um artefato cultural recente, a internet é a grande responsável pelas transformações nas formas como organizamos as estruturas sociais e o instrumento pelo qual estamos experimentando novas formas de narrar nossas biografias, criando outras maneiras de expressar subjetividades e de estabelecer relacionamentos. Mudaram também as formas tradicionais de trabalho e divertimento, incluindo nossa relação com o acúmulo de conhecimento social e científico e a introdução de novos processos poéticos às criações artísticas.

Talvez, há vinte e cinco anos, quando Donna Haraway (1991) escreveu o profético Manifesto Ciborg, nem a autora poderia imaginar como as tecnologias transformariam o cotidiano das pessoas, tampouco, como suas propostas continuariam a despertar inquietações e novas provocações. Nesse ensaio, Haraway, com a intenção de desestabilizar as categorias tradicionais de identidade, gênero e sexualidade, apresentou a metáfora do ciborg, um representante de uma subjetividade não baseada em identificações tradicionais, um híbrido questionador da identidade estática, que autorrevela um corpo que não é dado apenas biologicamente, mas se configura como um recipiente de códigos sociosimbólicos que ajudam a entender as novas relações de saber e poder, produzindo, também, novos sujeitos.

O ciborg de Haraway (1991) almejava ser o representante de uma nova trama social, um sujeito que, ao se apropriar das tecnologias, poderia ampliar o campo das ações subversivas e romper definitivamente com o sistema patriarcal. Passados poucos anos desde a popularização das mídias digitais, as experiências demonstraram que os ciberespaços reproduzem as mesmas estruturas sociais e os mesmos repertórios culturais do mundo offline. Assim, nossas atividades nos ciberespaços também refletem parte do que somos e as tecnologias, por si só, não foram capazes de transformar as relações desiguais de poder.

No entanto, apesar das imensas brechas, a internet se tornou uma ferramenta inquestionável e imprescindivel em quase todas as atividades humanas. Com o passar do tempo, a metáfora do ciborg foi se configurando no interior dos imaginários sociais não como um ser dotado de implantes ou próteses cibernéticas, em sujeitos conectados a uma "placa mãe" universal e acolhedora de todas as subjetividades. O ciborg, hoje, são todas as pessoas que transitam em mundos digitais e cuja familiaridade com as tecnologias provocou deslocamentos nas formas de pensar o sujeito e seus processos de subjetivação. Para algumas pessoas e grupos sociais, esses espaços se transformaram também em lugares para a agência política da identidade e um território favorável a explorações de narrativas alternativas e trocas de experiências.

Entendo que todas as ações mediadas pelas tecnologias, para subverter e confrontar as questões derivadas do patriarcado, são práticas feministas. Em outras palavras, quando 
uma mulher cria um meme para ironizar o machismo, isso é digifeminismo. Quando outras mulheres usam seus perfis nas redes sociais para expressar opiniões ou denunciar comportamentos sexistas, isso é digifeminismo. Quando as mulheres se interessam em aprender técnicas para se proteger, como a criptografia e o desenvolvimento de aplicativos e linguagens de programação, por exemplo, isso é digifeminismo. Quando criam blogs e páginas pessoais, para discutir sobre o empoderamento da mulher, isso é digifeminismo.

Meu interesse pelas culturas digitais nasceu no desenvolvimento de meu projeto de pós-graduação, no qual estudei as formas como as identidades não heteronormativas habitam os espaços mediados para narrar fragmentos de suas vidas e percepções do mundo (ABREU, 2014). A partir de então, usando abordagens metodológicas híbridas, como a netnografia e a análise de conteúdo, pesquiso as práticas de subjetividades usadas pelos sujeitos nos espaços digitais, entre elas as ações políticas, teóricas e artísticas das feministas na internet.

O ciberfeminismo, revisitado neste artigo, surgiu no final do século XX, a partir do reconhecimento das novas possibilidades oferecidas pelas tecnologias ao ativismo, ao pensamento político e à criação feminista. Era formado por mulheres envolvidas com a informática e a produção artística, engenhosas, agressivas e irreverentes com o politicamente correto. Para as ciberfeministas, as tecnologias implicavam a subversão das identidades essencialistas e dos padrões convencionais dos papéis de gênero, concentrando-se nas relações hierárquicas de poder que excluíam as mulheres das áreas de desenvolvimento tecnológico. Investigaram como as ferramentas tecnológicas as afetavam e defendiam a criação de espaços a partir de novas formas de participação ativista na internet.
Para entender melhor essa história, esboço uma breve trajetória sobre as primeiras investigações feministas nos ambientes digitais, que influenciaram e colaboraram para o surgimento do ciberfeminismo. Em seguida, discuto algumas estratégias feministas atuais e apresento um pequeno recorte de algumas artistas digifeministas que se destacam no cenário artístico contemporâneo. A intenção é discutir como os ciberespaços continuam desempenhando o papel de plataforma para a atuação de uma frente formada por mulheres que invadem os ambientes tecnologicamente mediados com questionamentos e sarcasmo aos códigos patriarcais, e, apesar de agirem de forma diferente da idealizada pelas primeiras ciberfeministas, essas jovens continuam construindo novas formas de agência política, buscando narrativas de enfrentamento aos códigos normativos, por meio das ferramentas tecnológicas.

Hoje, dificilmente podemos falar de feminismos sem considerar a atuação dos movimentos nas redes digitais. Muitas vezes, os coletivos feministas representam grupos que se encontram presencialmente, cujas atividades se expandem para a web, conectando militantes ou simpatizantes, em diferentes pontos geográficos; outras vezes, os grupos existem apenas on-line e, em muitas ocasiões, as digifeministas contemporâneas não formam parte de coletivos e suas ações são iniciativas individuais. De qualquer forma, definitivamente, as ferramentas tecnológicas possibilitaram a globalização das agendas ativistas feministas e potencializaram as discussões sobre as relações sexistas desiguais, além de colaborar para a visibilização de uma nova geração que parece não mais pertencer à noção de "sexo frágil".

Desde o início de nossas experimentações com as tecnologias, o ativismo feminista situou-se como um elemento ruidoso na inter- 
net, organizando espaços de participação em muitas frentes: ativismo social, hackativismo ${ }^{1}$ e artivismo, ${ }^{2}$ movimentos interseccionados que multiplicaram as esferas de atuação feminista. Todas as ações compartilhavam o desejo de justiça social, maior empoderamento e envolvimento das mulheres nas lutas políticas, para combater o modelo heteropatriarcal.

Do final do século XX aos dias atuais, muitas coisas mudaram. A internet transformouse em um enorme rizoma de muitas arenas sociais, políticas e econômicas, em um espaço privilegiado para o reconhecimento e a visibilidade de grupos sociais que tiveram seus direitos cassados, punidos ou silenciados ao longo da história. Mas esse contexto não foi construído da noite para o dia. Foram necessárias muitas experimentações, pesquisas e estudos teóricos, para começarmos a entender a influência das tecnologias em nossas vidas. A seguir, um pouco dessa história.

\section{Antecedentes teóricos do ciberfeminismo}

No final do século XX, a internet era considerada um espaço libertador e emancipador, um lugar onde qualquer um poderia assumir a representação que desejasse. A proposta ousada e inovadora de Haraway (1991) de pensar a relação entre os sujeitos e as tecnologias foi acompanhada pelas feministas da época com uma euforia marcada pela ingenuidade de quem apenas iniciava as primeiras experiências nas recém-lançadas redes informáticas.

É importante recordar que a década de 1990 foi um momento de muitas rupturas epis-

1 Hacktivismo é o acrônimo de hacker e ativismo. É a utilização de ferramentas digitais com fins políticos, utilizando, para tanto, alterações nos códigos das páginas web, bem como o desenvolvimento de softwares que potencializem ações ou estratégias de desobediência civil.

2 Artivismo é a junção das palavras Arte e Ativismo. temológicas e também palco para o surgimento de novas contribuições teóricas. Foi nessa época que estudiosos como Butler (1990), Sedgwick (1990), Fuss (1991), de Lauretis (1991), Warner (1993) e Halperin (1995), por exemplo, começaram a desenvolver suas críticas à heterossexualidade como norma compulsória, somando-se aos teóricos e teóricas que questionavam a noção tradicional de pensar as identidades como fixas e estáveis.

Nesse contexto de efervescências teóricas, as contribuições de Haraway (1991) foram particularmente relevantes para compreender uma sociedade que perdeu a ilusão na estabilidade da identidade e começou a aprender a viver em contextos de fluxos e fragmentações. O ciborg, segundo Ana Martínez-Collado (2005, p. 289) foi, provavelmente, o último grande mito moderno. Haraway (1991), naquela época e de forma profética, previu mudanças substanciais em nossas formas de pensar e construir as identidades e, com elas, as formas de representações identitárias.

Foi nesse contexto que apareceram as primeiras manifestações feministas na internet, tanto no âmbito teórico, como no campo criativo. Um grupo significativo de mulheres começou a realizar uma produção significativa, em blogs, listas de e-mails e grupos de discussões on-line, onde pensavam a produção do desejo, os significados do corpo da mulher, os discursos de poder e a produção de afetos e novas representações sociais vinculadas ao digital e à construção da subjetividade feminina.

Embora os primeiros estudos indiquem uma convergência com os ideais romantizados que acompanharam nossas primeiras explorações com as ferramentas digitais, é importante ressaltar que foram as estudiosas acadêmicas as primeiras a escrever e se interessar pelas práticas dos sujeitos no ambientes on-line. Nesse ponto, é inevitável citar o clássico Life on the Screen de Sherry Turkle (1995), no qual 
a autora exalta a possibilidade de criar múltiplas identidades e experimentar papéis distanciados dos "eus" reais. Ainda apoiada na natureza predominantemente textual da internet na década de 1990, esse estudo de Turkle (1995) colaborou para formar um imaginário romantizado das ciberculturas, lugares onde tudo era possivel, inclusive a descorporificação do gênero e da sexualidade.

Além de Haraway (1991), as teóricas feministas que mais receberam projeção no universo das investigações das influências das tecnologias no final do século XX foram Sadie Plant e Sandy Stone, pesquisadoras consideradas precursoras do ciberfeminismo.

A britânica Sadie Plant lecionou Estudos Culturais na Universidade de Warwick e foi diretora fundadora do Centro de Investigação de Cultura Cibernética, na Inglaterra. Ela deixou a academia em 1997, para escrever e pesquisar em tempo integral. Plant (1998) defende a ideia da internet como um território essencialmente feminino, onde sua própria estrutura permitiria a potencialização de uma comunicação mais homogênea entre homens e mulheres. Em seu célebre livro Zeros + Ones: Digital Women + the New Technoculture, lançado em 1997, a autora, a partir da história de Ada Lovelace, a primeira programadora do mundo, explorou a relação entre as tecnologias e as mulheres, argumentando que a mulher, representada pelo zero, corresponde ao vazio, à ausência dos sistemas de representações e, o homem, indicado pelo número 1, é o todo ou o conjunto da totalidade (PLANT, 1998, p. 41).

Passados dez anos, essa obra de Plant (1998) é analisada atualmente com olhos mais críticos que questionam a linguagem binária do computador ( 0 e 1) adotada pela autora para abordar as relações entre homens, mulheres e tecnologias. Os argumentos apontam que essa perspectiva vai na contramão das reflexões feministas atuais, cujas ações buscam a desconstrução do alinhamento entre sexo, gênero e orientação sexual.

Já a teórica Sandy Stone, uma das responsáveis em introduzir os estudos transgêneros na academia, é fundadora do ACTLab, um laboratório experimental, surgido em 1993, formado por artistas, pesquisadoras, professoras e hackers. Também é professora no departamento de Rádio-TV-Filme, da Universidade do Texas, em Austin. Stone (1991) investiga as questões relacionadas à interface, interação e agência, desde uma perspectiva feminista. Em seu conhecido ensaio Will the Real Body Please Stand Up? (1991), a pesquisadora analisou a construção do corpo e do desejo nas comunidades on-line e defendeu a ideia de que as diferenças e desigualdades entre os gêneros também são evidentes nos espaços mediados, pois nesses ambientes prevalecem os mesmos repertórios culturais vivenciados no mundo off-line. Para a teórica, o corpo digital tende a receber os mesmos códigos de gênero e de sexualidade previstos no sistema presencial e, embora na internet existam mais possibilidades de subverter as normas sociais, persiste a estrutura heteronormativa.

Lori Kendall (2002), professora na Universidade de Illinois, desenvolveu uma etnografia representativa para os estudos das ciberculturas a partir de suas experiências em um fórum de discussão on-line, no qual examinou como as pessoas construíam suas representações e negociavam os padrões de gênero nesse ambiente. Kendall (2002) percebeu que a maioria das pessoas prefere construir suas representações similares às suas identidades off-line. Segundo a autora, esse comportamento reproduz as construções sociais que reforçam o gênero e a sexualidade normativa também na Web.

$\mathrm{Na}$ mesma linha de pensamento, a holandesa e teórica feminista Liesbet van Zoonen (2002) considera as tecnologias como algo predominantemente masculino, pois os desenvol- 
vedores de programas, aplicativos e interfaces dos meios de comunicação são, na maioria, do sexo masculino. No entanto, a pesquisadora aponta as potencialidades da internet para a criação de novas oportunidades políticas às mulheres, ao oferecer um espaço de expressão particularmente relevante para a formação de redes e coletivos.

Jenny Sundén, professora na Escola de Gênero, Cultura e História da Universidade de Södertörn, na Suécia, em seu livro Material Virtualities (2003), trouxe novas problemáticas para o campo dos estudos das ciberculturas. Nesse trabalho, Sundén (2003) se concentrou em desconstruir algumas ideias iniciais das investigações relacionadas aos ciberespaços, quando prevaleceu uma perspectiva demasiadamente otimista e ingênua. No livro, a pesquisadora discute a importância da construção do corpo nas experiências das identidades mediadas pelas tecnologias e questiona a visão utópica de desmaterialização do corpo nas plataformas digitais. Sundén (2003) propõe uma interpretação feminista do ciborg que destaque as experiências reais dos sujeitos e sugere uma abordagem sensivel das construções de identidades digitais, cujas corporeidades continuam sendo o foco das relações estabelecidas nos ambientes mediados.

$\mathrm{Na}$ Espanha, Remedios Zafra (2005), escritora e professora na Universidade de Sevilla, no livro Netianas. $N(h)$ acer mujer en Internet ressaltou a importância do corpo na configuração da identidade digital e propõe o conceito netiana, para descrever diferentes possibilidades e devires de "existir" como sujeito feminino nas plataformas digitais. Para Zafra (2005), a netiana é consciente das cargas simbólicas que reproduzem os comportamentos, valores, as discriminações e os estereótipos nos espaços mediados, inclusive, em muitas ocasiões, reforçando-os. No entanto, nesses ambientes, as formas de resistência e articulação política são representadas de maneira dispersa, por meio da ação de pequenas células de poder móveis que favorecem a construção de identidades mais flexíveis, onde os sujeitos dispõem de um conjunto de ferramentas que podem ser usadas criativamente para elaborar a presença on-line (2005, p. 28).

Judy Wajcman, professora de Sociologia na Escola de Economia e Ciência Política de Londres, autora do livro Tecnofeminismo (2006), elaborou uma crítica contundente à ideia da internet como um meio homogeneizador das diferenças. Segundo Wajcman (2006), essa perspectiva induz uma visão essencialista da categoria "mulher" e a autora questiona a relação simplista onde as tecnologias são sinônimos de liberdade ou neutralidade identitária, argumentando que o desenvolvimento das tecnologias sempre foi um território masculino. Wajcman (2006) defende o "tecnofeminismo" como forma política de resistência às características patriarcais das redes informáticas e faz um convite às mulheres para romper com o controle das tecnologias, passando a integrar, desde dentro, as mudanças proporcionadas pela indústria cultural e tecnológica.

Após 2007, com a explosão das redes sociais e a popularização dos artefatos eletrônicos, sobretudo dos telefones móveis, as redes digitais despertaram o interesse de muitas investigadoras feministas que perceberam o impacto proporcionado por essas ferramentas e sua relevância nas práticas cotidianas. Hoje, temos um vasto repertório bibliográfico, com abordagens feministas nos estudos das culturas digitais.

\section{Revisitando o ciberfeminismo}

O ciberfeminismo surgiu no contexto das teorias pós-estruturalistas e das tendências da chamada terceira onda dos feminismos. Apesar de não ter definido nenhuma postura política, o ciberfeminismo converteu-se em um 
campo de atuação política e artística importante para o movimento, cujas ações buscaram o confronto contra os discursos da normatividade essencialista instituída pelo sistema heteropatriarcal. 0 ciberfeminismo adicionou às demandas feministas a análise das ciberculturas e a construção do gênero nos ciberespaços, além de lutar contra as características sexistas que excluem as mulheres da cultura e do desenvolvimento tecnológico, cenário no qual, ontem e hoje, permanece sob o domínio e o controle masculino.

O ciberfeminismo nasceu com grandes expectativas utópicas e adotou muitas estratégias no início da internet, como listas de discussão via e-mails, fóruns on-line, grupos de autoajuda e redes de apoio, além de incentivar as mulheres não só a participar dessas iniciativas, mas compartilhar saberes e construir conhecimento no desenvolvimento de softwares, plataformas digitais, linguagens de programação e o uso das tecnologias como suporte e expressão artística. A ideia era transformar as desigualdades, combater a centralização dos poderes hierarquizados a favor de trocas mais horizontais, outorgando às mulheres um espaço público acessível para planos de ação e envolvimento político por meio das tecnologias.

Ileana Stofenmacher (2002), pesquisadora argentina, explica o surgimento do ciberfeminismo a partir de duas vertentes distintas que ocorreram de forma simultânea. A primeira, comentada anteriormente, surge com Sadie Plant, na Inglaterra, que passou a usar o termo para descrever o relacionamento e o envolvimento das mulheres com as tecnologias. A segunda vertente surgiu na cidade de Adelaide, Austrália, precisamente no verão de 1991, a partir da união de quatro artistas: Francesca da Rimini, Julianne Pierce, Josephine Starrs e Virginia Barratt. Elas se autointitulavam ciberfeministas e formaram o provocativo grupo:
VNS Matrix ${ }^{3}$ (VeNuS Matrix), cuja produção as artistas denominavam cunt art. Francesca da Rimini, também conhecida como Gashgirl e Doll Yoko, conta como nasceu o Grupo:

Como toda boa história de coagulação, começa com fluidos viscosos e talvez terminará em sangue. [...] Rotulamos o vírus da nova desordem mundial impulsionadas pelo vinho tinto e as babas vaginais (que só podiam se recompor se nos dedicávamos com frequência às distrações prazerosas). (MARTÍNEZ-COLLADO, 2001, p. 220, tradução nossa $)^{4}$

Segundo Remedios Zafra (2004), as produções teóricas de Sadie Plant e as artísticas de VNS Matrix apresentavam semelhanças em relação à necessidade de uma "feminização" do desenvolvimento e uso das ferramentas tecnológicas, mas possuíam formas diferentes de aproximação do ciberfeminismo. Para Plant (1998), a identificação entre mulher e tecnologias era algo natural e automático, enquanto que para as integrantes de VNS Matrix, a intervenção política e a agência feminina eram elementos imprescindiveis. Plant (1998), teoricamente, foi criticada por ser excessivamente otimista, enquanto VNS Matriz partiu de uma perspectiva de enfrentamento artístico e, como Zafra (2004) identifica, introduziram na internet um viés inovador para desafiar os códigos normativos.

A estratégia usada por VNS Matrix era a utilização da ironia e da subversão dos códigos simbólicos do sistema patriarcal. Não é casualidade que o ano de formação do Grupo, em 1991, seja o mesmo do lançamento do livro Gender Trouble (2007), um clássico de Judith Butler, no qual a autora defende a ideia que o feminismo deveria estabelecer uma "política

3 Disponivel em: <http://vnsmatrix.net/>.

4 Tradução livre de: "Como toda buena historia de coagulación, empieza con fluidos viscosos y quizás terminará en sangre. [...] Etiquetamos el virus del nuevo desorden mundial impulsadas por el vino tinto y las babas vaginales (que sólo podían reponerse si nos dedicábamos con frecuencia a actividades placenteras)". 
paródica da mascarada", justamente para converter a repetição das práticas em potência de transformação das agências políticas das subjetividades.

As artistas de VNS Matrix, inspiradas nos estudos teóricos das feministas da época, adotaram as ferramentas tecnológicas para executar suas ideias e desenvolver uma série de trabalhos que abordavam as problemáticas da relação entre a mulher e as tecnologias, utilizando como estratégia a provocação, a inversão de estereótipos culturais e uma política de confronto sem recalques ou melindres. Uma de suas primeiras intervenções foi a criação do bombástico e despudorado Manifesto Ciberfeminista para o Século XXI (1991), uma homenagem a Haraway, cuja frase "o clitóris é uma linha direta à matriz", tornou famoso o grupo e virou uma espécie de lema do ciberfeminismo, uma vez que ressalta a estreita relação entre as mulheres e as tecnologias, o corpo feminino e a máquina:

Nós somos a buceta moderna; positivo anti-razão; sem amarras desenfreadas, sem perdão; vemos arte com nossa buceta, fazemos arte com nossa buceta; acreditamos no gozo loucura o sagrado e poesia; somos o vírus da nova desordem mundial; rompendo o simbólico de dentro para fora; sabotadoras do sistema do big daddy; o clítoris é uma linha direta para a matriz. VNS MATRIX. Exterminadoras do código moral; mercenárias do lodo; caímos do altar da abjeção; cutucando o templo visceral nós falamos em línguas; infiltrando interrompendo disseminando; corrompendo o discurso; somos a buceta do futuro. (Manifesto Ciberfeminista, VNS Matrix, 1991, tradução nossa) ${ }^{5}$

5 Tradução livre de: “We are the modern cunt; positive anti reason; unbounded unleashed unforgiving we see art with our cunt we make art with our cunt; we believe in jouissance madness holiness and poetry we are the virus of the new world disorder; rupturing the symbolic from within saboteurs of big daddy mainframe; the clitoris is a direct line to the matrix. VNS MATRIX. terminators of the moral codes mercenaries of slime; go down on the altar of abjection; probing the visceral temple we speak in tongues; infiltrating disrupting disseminating corrupting the discourse; we are the future cunt". Disponivel em:
As criações de VNS Matrix questionavam o patriarcado e suas atividades artísticas exploraram outras formas de representação do corpo, da sexualidade e da subjetividade feminina, posicionando-se contra os discursos machistas, o controle e a dominação masculina no desenvolvimento das tecnologias. O Grupo ganhou projeção na Austrália, EUA e em alguns países da Europa, expandindo-se rapidamente pela internet, incorporando novas formas de atuação e estratégias de oposição às políticas sexistas, em várias partes do mundo.

Outro momento marcante da história do ciberfeminismo aconteceu em setembro de 1997, na I Conferência Internacional Ciberfeminista, em Kassel, Alemanha, por ocasião do Documenta $X$, uma mostra internacional de arte contemporânea. O Encontro foi organizado pelo grupo europeu Old Boys Network (OBN), ${ }^{6}$ formado por Faith Wilding, Cornellia Solfrank, Yvonne Volkart e Helene von Oldenburg. Nos debates acalorados, as participantes do Encontro optaram por não conceituar o ciberfeminismo e, no lugar de respostas categóricas, elaboraram uma lista de 100 antíteses ou definições sobre o que o ciberfeminismo não era, evocando a indefinição como arma de intervenção política. Essa decisão teve a intenção de atrair mulheres de diversas áreas de atuação e tendências, especialmente as mais jovens, que demonstravam pouco interesse pelas histórias e teorias feministas, ainda que se definissem como ciberfeministas. Alguns trechos do Manifesto:

1. O ciberfeminismo não é uma fragrância

4. O ciberfeminismo não é uma ideologia

10. O ciberfeminismo não é uma práxis

18. O ciberfeminismo não é um ismo

19. O ciberfeminismo não é anti-masculino

24. O ciberfeminismo não é apolítico

83. O ciberfeminismo não tem a ver com brinquedos chatos para garotos chatos

<http://www.sterneck.net/cyber/vns-matrix/index. php>. Acesso em: 16 nov. 2016.

6 Disponivel em: <http://www.obn.org/>. 
99. Ciberfeminismo não é estável

100. Ciberfeminismo não tem somente uma linguagem.?

A falta de uma definição política clara para explicar o ciberfeminismo incomodou algumas feministas acadêmicas e de alguns movimentos organizados que cobraram estratégias de ações políticas mais diretivas contra o status quo do patriarcalismo. Essa crítica, provavelmente, está relacionada com certa euforia diante das potencialidades tecnológicas, uma característica marcante de nossas primeiras explorações nas interfaces digitais. Com o passar do tempo, a ideia da internet como um espaço libertador e unificador foi sendo paulatinamente diluída, conforme fomos acumulando experiências com os artefatos tecnológicos.

Atualmente, as redes digitais configuram um enorme rizoma, um contexto impossivel de ser imaginado há 25 anos atrás. As expectativas do ciberfeminismo em relação à ordenação e à organização coletiva do movimento, para criar uma identidade política e uma unidade aglutinadora em torno do uso das tecnologias se mostraram pouco efetivas diante do rápido crescimento e da fragmentação da internet. Em realidade, o ciberfeminismo configurou-se como um conjunto híbrido de trabalhos, ações e investigações que não esboçaram um projeto único. Suas atividades multidisciplinares caminharam mais em direção ao intercâmbio de experiências e à heterogeneidade dos discursos, produções e posicionamentos políticos.

Quando a internet apenas engatinhava, as ciberfeministas abriram muitos espaços no disputado território (masculino) das redes digitais. Criaram essas aberturas para se informar e organizar em coletivos, criticar os comportamentos sexistas, estabelecer alianças e ampliar o alcance para a experimentação de novas formas de expressão artística.

7 As 100 antíteses estão disponíveis em: <http://www. obn.org/cfundef/100antitheses.html>. Acesso em: 22 nov. 2016.
A provocação e o deboche foram as armas mais utilizadas pelo ciberfeminismo e seguiram os passos deixados pelas artistas feministas da década de 1980, como Judy Chicago, Cindy Sherman e Barbara Kruger, a diferença era o alcance dos e das espectadoras e o suporte utilizado. Faith Wilding é outra referência importante para o ciberfeminismo. Artista multidisciplinar, nascida no Paraguai, Wilding emigrou para os Estados Unidos da América do Norte, em 1961, e ficou conhecida ao performar o monólogo Waiting, no projeto de arte feminista Womanhouse, idealizado por Judy Chicago, em Los Angeles, no início de 1970. Essa performance virou uma espécie de ícone da performance feminista e fonte de inspiração para as ciberfeministas.

Coincidentemente, o ciberfeminismo nasceu no mesmo momento da Net-Art e, provavelmente, as ciberfeministas reconheceram na internet um contexto favorável e privilegiado para a produção artística, pois funcionava independente dos sistemas fechados das galerias e dos museus, nos quais a inserção de mulheres sempre foi estatisticamente minoritária. Remedios Zafra acrescenta que:

As novas possibilidades de trabalho (tanto de produção como distribuição) fornecidas pela Internet permitiu às artistas a criação de redes autônomas independentes das estruturas hierárquicas próprias da instituição-Arte. Além disso, a crítica às lógicas lineares e excludentes características dos discursos essencialistas tem nas novas linguagens da rede (com base em estruturas horizontais e uma linguagem fragmentada e hipertextualizada) uma possibilidade de ação subversiva sem precedentes. (ZAFRA, 2004, $\mathrm{s} / \mathrm{n}$, tradução nossa) ${ }^{8}$

8 Tradução livre de: "Las nuevas posibilidades de trabajo (tanto producción como distribución) brindadas por Internet permiten a las artistas la creación de redes autónomas independientes de las estructuras jerárquicas propias de la institución-Arte. Por otra parte, la crítica a las lógicas lineales y excluyentes características de los discursos esencialistas tiene en los nuevos lenguajes de la red (basados en estructuras horizontales y en un lenguaje fragmentado e hipertextualizado) una posibilidad de acción subversiva sin precedentes". 
Os ambientes digitais tornaram-se um universo sedutor para as ciberfeministas e excepcionalmente produtivo para suas experiências criativas.9 Um exemplo conhecido é a artista estadunidense Kathy Rae Huffman que, em conjunto com a alemã Eva Wohlgemuth, desenvolveu muitas obras usando as ferramentas tecnológicas, se destacando Face Settings (1996-1998), cuja reverberação originou um mailling list apenas de mulheres do âmbito do ciberfeminismo e da arte ciberfeminista. Outro exemplo é o da artista Linda Dement, com a obra digital Cyberflesh Girlmonster (1995), una justaposição de imagens de partes de corpos femininos, em que a artista acrescentou textos e sons que formam seres híbridos e curiosos, capazes de se multiplicarem com a ação/interação dos(as) usuários(as).

Imagem do projeto Cyberflesh Girlmonster, de Linda Dement. $^{10}$

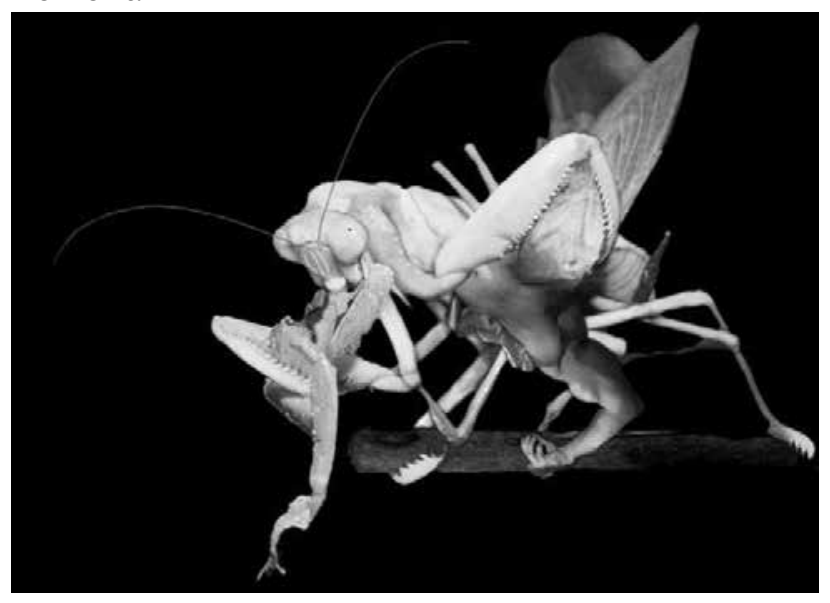

A primeira década do século XXI serviu para dissipar definitivamente as expectativas utópicas do início do ciberfeminismo. As mulheres envolvidas nesse movimento deram-se conta de que as almejadas transformações sociais não se realizariam baseadas apenas nas tecnologias. Os problemas e as desigualdades

9 Uma lista ampla de artistas ciberfeministas pode ser encontrada neste link: <http://www.estudiosonline. net/art/index.htm>.

10 Disponivel em: <http://www.lindadement.com/cyberflesh-girlmonster.htm>. Acesso em: 20 nov. 2016. originadas das construções sociais são questões que assumem formas complexas e interseccionais, portanto, globalizadas, e, ao mesmo tempo, ajustadas a contextos específicos.

A fantasia criada de pensar as redes digitais como espaços não hierárquicos de poder sugeriu a muitas ciberfeministas a ideia de uma unidade universal. O movimento criou uma espécie de ilha ou bolha utópica, comportamento que se explica quando retomamos o início dessa história, período em que era comum pensar que a ausência do corpo e o anonimato nos ciberespaços faziam desaparecer as diferenças de gênero e de sexualidade (TURKLE, 1995).

0 anonimato, defendido pelas ciberfeministas como a chave para as ações subversivas, fazia parte da ilusão de que para a identidade digital, tudo era possivel, porque não podiam ser vigiadas ou descobertas. Hoje, o contexto é bastante diferente. A internet transformou-se em inúmeras células e desenvolvemos outras formas para mover-nos por esses espaços. 0 anonimato continua a ser usado, especialmente para atacar e denegrir de forma covarde nas mídias interativas, mas, caso haja intervenção jurídica e investigação policial, a pessoa pode ser localizada.

Os espaços mediados já produziram muitos casos que exemplificam a falta de sensibilidade por parte da sociedade em relação às questões de gênero, sexualidade e raça, reproduzindo e difundindo comportamentos abusivos, exclusões, violências, tratamentos degradantes e intolerâncias. Por outro lado, a expansão das redes digitais também significou uma ampliação sem precedentes das possibilidades de colaboração, participação e ações coletivas de grupos que historicamente tiveram seus direitos cassados, diminuídos ou dificultados. Além disso, a intensa penetração das tecnologias nas práticas cotidianas favoreceu a multiplicação do pensamen- 
to feminista e de suas atividades de combate às discriminações e opressões, não mais se restringindo a contextos geograficamente localizados.

De qualquer forma, as estratégias ciberfeministas do final do século passado abriram portas e janelas para as ações de uma legião de jovens que se identificam com suas propostas. Hoje, os digifeminismos se mantêm ativos, contestatários e estão presentes em muitos espaços on-line para se manifestarem contra os discursos da supremacia masculina, marcar presença ativa e representatividade.

\section{As meninas boas vão para o céu, as más viram digifeministas}

O termo digifeminista é usado neste artigo para pensar a geração de jovens mulheres que atualmente habitam os ambientes mediados e de maneira similar às ciberfeministas do passado, se empenham na construção de uma internet feminista e usam as ferramentas digitais para expressar opiniões, organizar campanhas e exibir suas produções textuais e artísticas.

Ainda que a expansão e a popularização da internet nos últimos anos também tenha aumentado as possibilidades de ataques machistas, racistas e homo/transfóbicos, as digifeministas esforçam-se na criação de espaços de visibilidade para a formação de comunidades de apoio, afinidades e resistências. Assim, discussões importantes sobre gênero, raça, poder e tecnologias estão acontecendo por toda a Rede e essas jovens já não aceitam que antigos tabus definam o que elas podem fazer, dizer ou ser.

A atuação da nova geração é bem diferente do cenário imaginado pelas ciberfeministas do passado, talvez porque as tecnologias de acesso e de interação também tenham mudado radicalmente. Os manifestos desvergonhados e os ataques cibernéticos foram substituídos por tweets, blogs, formação de grupos e produção de vídeos e imagens desafiadoras. Essas meninas se juntam para produzir fanzines, elaborar e executar protestos, fabricam memes e usam hashtags para organizar blocos de discussão temática. Essas estratégias podem não ser tão transgressoras como as usadas pelas ciberfeministas, mas, hoje, possuem um alcance inimaginável e cada vez mais incentivam as mulheres rumo aos feminismos.

As redes sociais, especialmente, têm alimentando o florescimento de feminismos plurais, diversos, participativos e contraculturais. Têm a cara da geração do século XXI, portanto, a dispersão e a fragmentação também fazem parte desses contextos. A partir de seus artefatos eletrônicos, essas mulheres se conectam desde muitos lugares para reivindicar a legalização do aborto, lutar contra o feminicídio, a violência de gênero, o acosso público e naturalizado nas ruas e os machismos cotidianos. Invadem as timelines dos perfis digitais, blogs, revistas digitais e qualquer lugar onde seja possivel expressar o repúdio aos comportamentos que as afetam e as diminuem em seus direitos e reivindicações.

Há muitos feminismos sendo alimentados on-line. Suas ações estão, pouco a pouco, transformando a compreensão sobre o que vem a ser "mulher" no século XXI. Por meio das ferramentas digitais, as lutas feministas, antes localizadas em seus territórios e contextos específicos, tornaram-se, rapidamente, a luta de milhares de mulheres que se solidarizam e se juntam em redes de apoio e de visibilidade.

Um exemplo recente foi o movimento \#NiUnaMenos, ressurgido na Argentina, por ocasião do brutal estupro e assassinato de Lucía Pérez, de apenas 16 anos, ocorrido em outubro de 2016. A hashtag NiUnaMenos foi inspirada 
no poema da mexicana Susana Chávez, escrito em 1995, para protestar contra o feminicídio na cidade de Juárez. A poetisa foi assassinada em 2011.

A mobilização \#NiUnaMenos nasceu nas redes sociais, convocou milhares de pessoas na América Latina e em distintos pontos do mundo e foi um movimento massivo e comovedor. Mas não foi a única hashtag a reunir multidões em torno de questões pontuais e ao mesmo tempo universais. Por exemplo, a hashtag \#BringBackOurGirls foi utilizada para denunciar o sequestro de centenas de meninas na Nigéria e replicou-se rapidamente por todo o mundo. \#HeForShe, contra a desigualdade de gênero, foi criada pela ONU Mulheres e impulsionada pela atriz Emma Watson. Tornou-se, também, viral e se multiplicou em muitas versões traduzidas para outros contextos.

No Brasil, mais ou menos a partir de 2013, a internet foi invadida por uma legião de jovens que aderiram às práticas feministas de resistência aos poderes hierárquicos. As teorias feministas, antes encerradas em alguns circuitos, grupos e eventos organizados geralmente por intelectuais universitárias, parecem finalmente pular os muros da academia e começam a fazer parte das ações cotidianas de muitas mulheres que atuam massivamente nas redes digitais.

Especificadamente nesse ano, em 2013, o coletivo feminista Think Olga lançou a campanha Chega de Fiu, contra o assédio sexual em espaços públicos. Inicialmente, a campanha deu-se por meio de uma série de ilustrações com mensagens de repúdio às cantadas baratas, atitudes grosseiras e comentários deselegantes que muitas mulheres recebem no dia a dia, mas, logo depois, se ampliou, gerando um movimento nacional contra o assédio público. Parte da campanha foi o lançamento de um aplicativo colaborativo,11 usado para mapear e

11 Disponivel em: <http://chegadefiufiu.com.br/>. registrar o assédio sexual e comportamentos machistas ofensivos.

No contexto brasileiro também é o comum o uso da hashtag como arma política de enfrentamento e coalização. Algumas tornaramse bastante populares, como foi o caso de \#primeiroAssédio, lançado em 2015, também uma iniciativa do coletivo Think Olga, depois que uma menina de 12 anos, participante do programa MasterChef Júnior, foi vítima de comentários de teor sexual nas redes sociais. A hashtag incentivou o depoimento de milhares de histórias de abusos e agressões sofridas por mulheres em todo o Brasil.

Por sua vez, \#MeuAmigoSecreto, criada em novembro de 2015, pelo coletivo feminista Não Me Kahlo, foi usada massivamente para relatar casos de assédio e comportamentos machistas por parte de amigos, colegas ou familiares, no ambiente de trabalho, nas universidades ou em qualquer ambiente público ou privado, sem revelar a identidade do acusado. Essa campanha expôs a naturalização do machismo no Brasil e também gerou um livro: \#MeuAmigoSecreto: feminismo além das redes (LARA; RANGEL et al., 2016), que reúne cinco artigos das integrantes do coletivo Não Me Kahlo, ${ }^{12}$ expandindo o debate sobre a desconstrução do machismo e a reverberação das mobilizações feministas em torno de temáticas comuns.

Há vários outros exemplos, como \#vamosFazerUmEscândalo, hashtag proposta pela vlogger Julia Tolezano,13 a Jout Jout, incentivando as mulheres a não se calarem diante de situações de assédio e abuso sexual. \#vaiTerShortinhoSim foi uma campanha lançada pelas estudantes do Colégio Anchieta, no Rio Grande do Sul, em protesto contra a proibição do uso de shorts nas dependências da escola. 0 proje-

12 Bruna de Lara, Bruna Rangel, Gabriela Moura, Paola Barioni e Thaysa Malaquias.

13 Disponivel em: <https://www.youtube.com/user/joutjoutprazer>. 
to \#vamosjuntas foi idealizado pela jornalista Babi Souza, para incentivar a união entre as mulheres contra a insegurança das ruas e no transporte público.

Em Goiás, uma página no Facebook chamada Indique uma mana!, ${ }^{14}$ um grupo composto exclusivamente por mulheres (cis e trans), pretende ajudá-las a se inserirem no mercado de trabalho e já conta, no momento em que escrevo essas linhas, com mais de 19 mil inscritas e centenas de posts oferecendo ou buscando oportunidades de trabalho.

As jovens feministas não ficam restritas às táticas de enfrentamento público, mas também se organizam em grupos fechados para aprender e ensinar linguagens e técnicas de programação, como o MariaLab, ${ }^{15}$ RodAda Hacker, ${ }^{16}$ Django Girls, ${ }^{17}$ PrograMaria, ${ }^{18}$ Luluzinha camp,$^{19}$ entre outros grupos que se encontram com frequência, on-line e off-line, e têm cumprido um papel importante na formação de novas programadoras.

Existem muitas páginas on-line que se posicionam abertamente contra os estereótipos e estigmas de gênero, de sexualidade e raça. São grupos, coletivos e iniciativas individuais que trazem uma brisa fresca aos moralismos sociais. Essas mulheres têm mudado a cara dos ambientes digitais e trazem pluralidade aos discursos feministas. Apesar da internet continuar sendo um espaço misógino e sexista, onde os ataques e abusos são comuns, continua sendo, como foi desde o seu surgimento, uma plataforma de atuação política e transformação social feminista.

\section{Artistas Digifeministas contemporâneas}

\footnotetext{
14 Disponivel em: <https://www.facebook.com/ groups/1762806147309719/?fref=ts .

15 Disponivel em: <http://marialab.org/>.

16 Disponivel em: <http://rodadahacker.org/>.

17 Disponivel em: <https://djangogirls.org/saopaulo/>.

18 Disponivel em: <https://www.programaria.org/>.

19 Disponivel em: <http://luluzinhacamp.com/>.
}

As manifestações artísticas feministas alastraram-se na internet e há de tudo, um pouco: vídeos, performances, poesias, contos, ilustrações, fotos e muitas páginas em redes sociais e websites, que ajudam na visibilização desses trabalhos. Essas artistas transitam pela Web como se estivessem em seus próprios quartos; algumas sabem programar e construir páginas interativas, outras produzem textos, imagens, vídeos, memes e gifs animados. Suas produções dão sinais claros que, para essa geração, o formato "bela, recatada e do lar" não representa mais a mulher contemporânea.

As artistas digifeministas normalmente são muito jovens, a maioria tem menos de 30 anos, portanto, cresceram familiarizadas com o digital. Suas estratégias nas redes digitais são parecidas com as usadas pelas ciberfeministas do passado, para desconstruir os estereótipos de gênero e questionar a cultura estabelecida, assim, a paródia e a provocação, sem a preocupação com o politicamente correto, são táticas frequentes.

A identidade, o corpo e a sexualidade são temas centrais em seus trabalhos e elas não se sentem intimidadas em se apropriarem de suas imagens corporais para expor e romper tabus. Como é o caso de Petra Collins, ${ }^{20}$ artista canadense nascida em 1992. É uma das grandes vozes da nova geração de fotógrafas e ficou conhecida, em 2014, quando o Instagram suspendeu sua conta após ela postar uma foto de biquíni em que apareciam alguns pelos pubianos. Após o incidente, a artista foi convidada pela marca American Apparel para desenhar a coleção de camisetas Period Power T-shirt, na qual tratou de explorar o tabu em torno da temática da menstruação.

20 Disponível em: <http://www.petracollins.com/>. 
Foto de Petra Collins censurada no Instagram. ${ }^{21}$

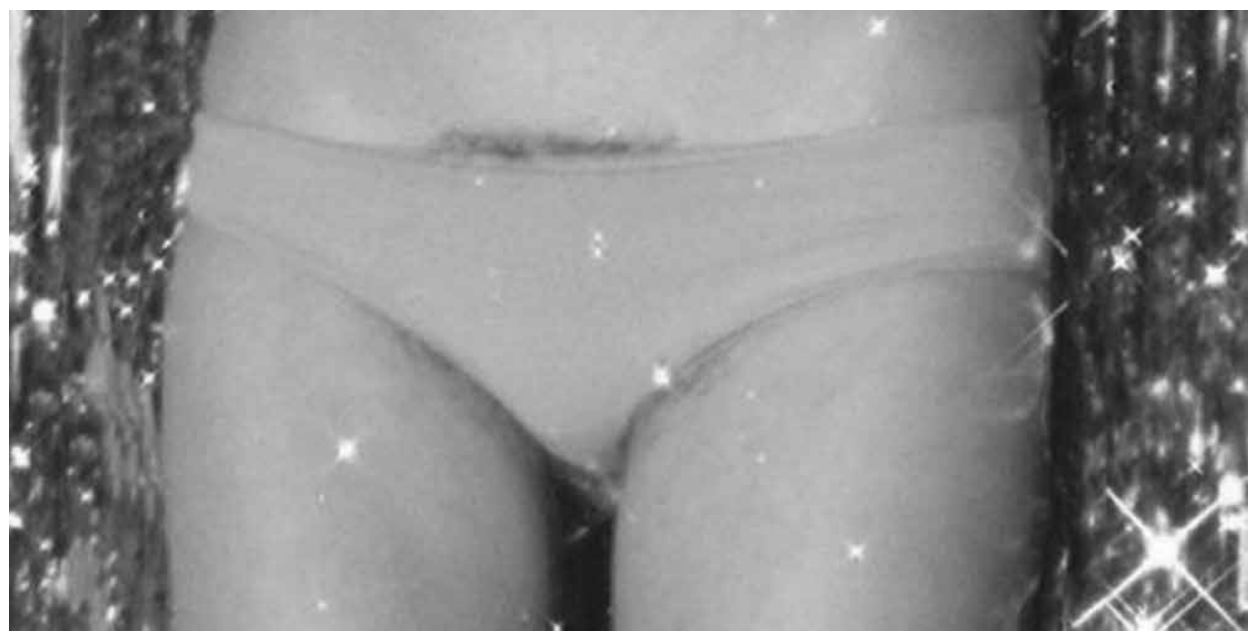

Outra artista bastante conhecida no meio das digifeministas é Molly Soda, nascida em San Juan, Puerto Rico, em 1989. Molly Soda cresceu em Bloomington, Indiana, EUA, e passou a ser conhecida a partir de sua conta na rede social Tumblr. ${ }^{22}$ Hoje, a artista tem perfis em várias redes para exibir seus projetos artísticos que trazem reflexões sobre os sentimentos de autoestima, inadequação e questionamentos sobre os padrões de feminilidade socialmente impostos.

Molly é da geração das selfies e muitas de suas fotos são autorretratos sem filtros ou efeitos especiais. Seu projeto mais conhecido é Deveria enviar essa? [Should I send this?], ${ }^{23}$ um fanzine digital com textos autorais e fotos de seu corpo que, segundo a artista, estavam guardadas em seu celular. 0 fanzine parece uma espécie de diário visual digital, registros da memória, um exercício de reflexão sobre o que deve ou não ser compartilhado na internet. Em uma das imagens, Molly mostra um fragmento de seu corpo, a barriga e o umbigo. Na imagem, claramente se vê que ela não está depilada. Essa foto se tornou viral, causou re-

21 Disponivel em: <http://www.huffingtonpost.com/ petra-collins/why-instagram-censored-my-body_b_4118416.html>. Acesso em: 25 nov. 2016.

22 Disponivel em: <http://mollysoda.tumblr.com/>.

23 Disponivel em: <https://newhive.com/mollysoda/ sendthis?q=\%40 mollysoda $\% 20 \% 23$ sent>. pulsão em algumas e adoração por parte de muitas outras mulheres que se identificaram com a artista.

Captura de tela do projeto "Should I send this?", de Molly Soda.

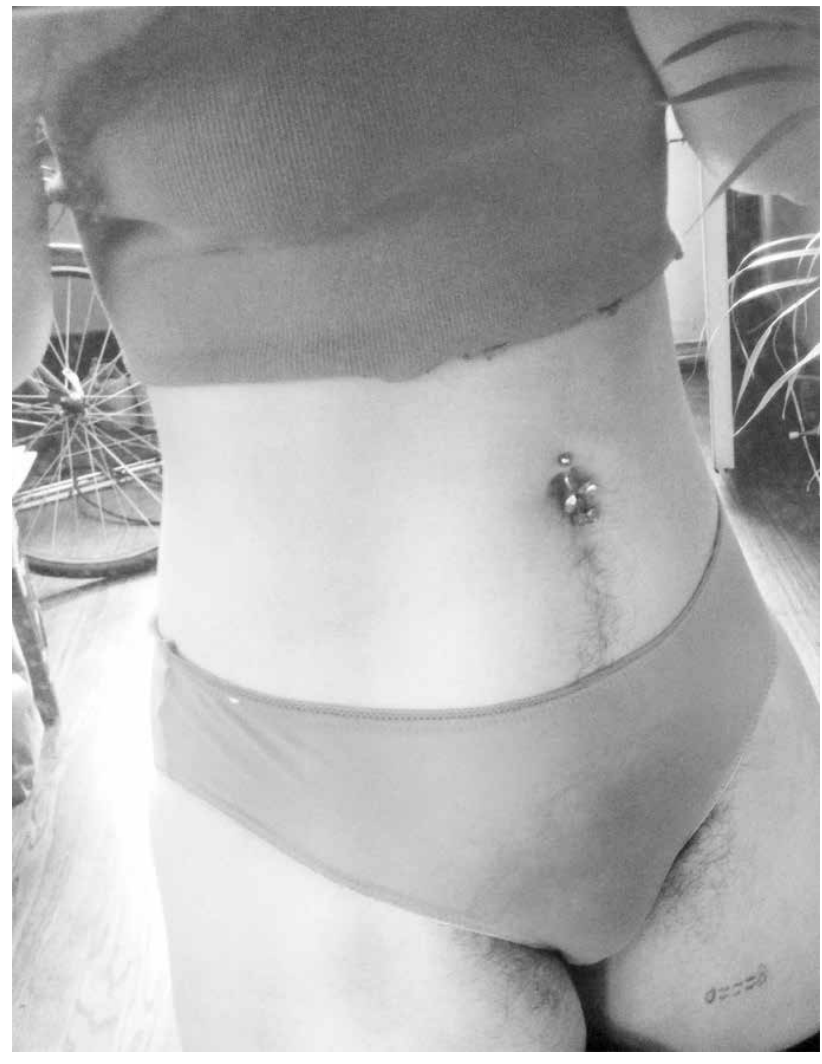

Petra Collins e Molly Soda usam as ferramentas digitais para desafiar as representações estetizadas do corpo feminino e, nos seus trabalhos, axilas com pelos, fluidos corporais e roupas intimas despretensiosas em relação ao olhar masculino, são orgulhosamente mos- 
tradas em seus perfis nas redes sociais e blogs pessoais. As artistas questionam os ideais de beleza e as fotos mostram corpos plurais, sem sutilidades e nem disfarces. Suas produções são atividades reflexivas sobre a construção da identidade mediada, dos significados de ser mulher, sobre intimidade e exibicionismo, e de como podemos construir nossas presenças on-line. A partir dessas ideias, elas indicam o caminho para uma sexualidade mais fluida, menos preocupada com os padrões de beleza criados por olhares e subjetividades masculinas.

A sueca Arvida Byström, ${ }^{24}$ nascida em 1991, também é outra artista conhecida no meio das digifeministas. Usa a internet como ferramen- ta e plataforma para a exibição de suas fotografias e vídeos, presentes em vários canais e redes sociais, especialmente o Instagram, ${ }^{25}$ onde possui mais de 160 mil seguidores. Apesar de muito jovem, suas imagens provocadoras chamaram a atenção de várias publicações e Arvida já fotografou para a revista de moda VICE, Wonderland Magazine, Mag Rookie, Garage, Dazed, entre muitas outras. A artista, parece não estar preocupada com a aprovação dos discursos que limitam suas narrativas visuais e suas fotografias revelam as intersecções entre sexualidade e gênero, imagens que desafiam as normas limitantes das expressões corporais femininas.

Capturas de tela do perfil de Arvida Byström no Instagram.
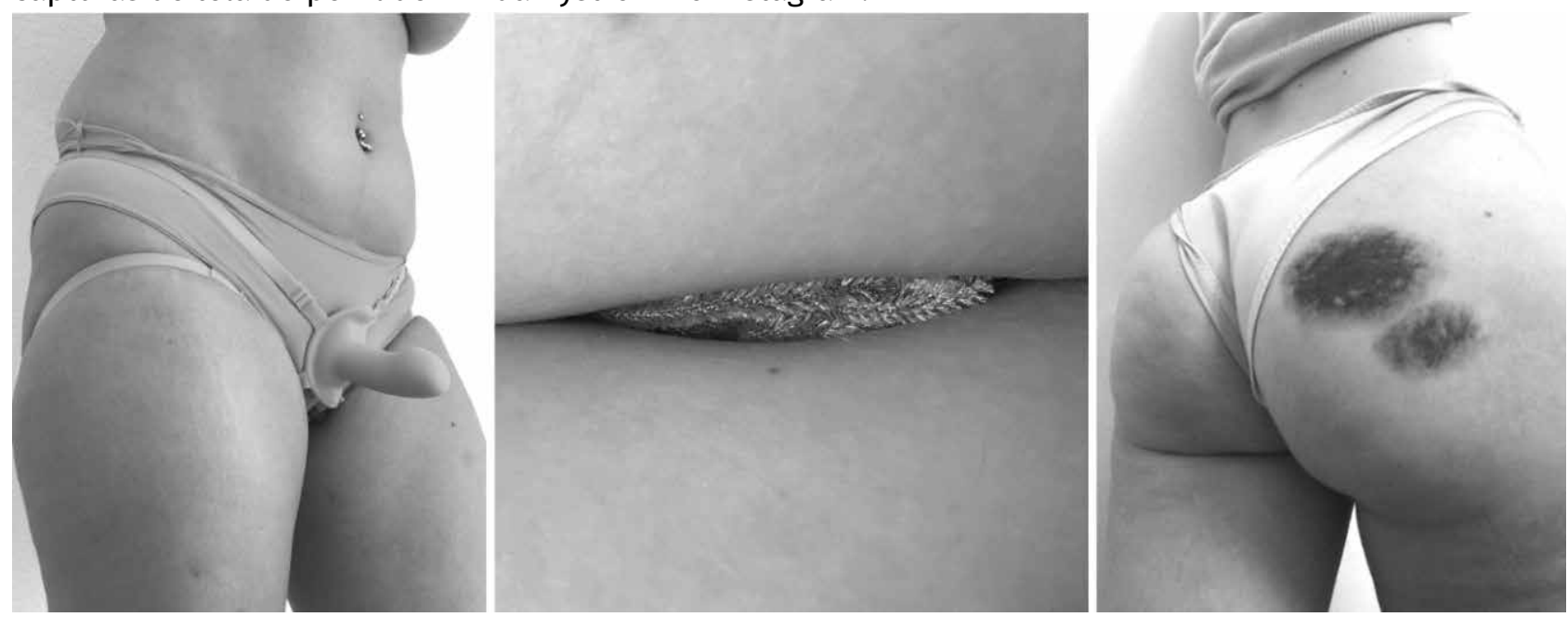

A lista de artistas digifeministas é grande e seria impossivel citar todas neste artigo. São mulheres produtoras de imagens e vídeos que rompem com a monotonia normativa presente nas visualidades digitais e provocam ruídos nas hegemonias construidas por olhares masculinos. Os fluxos de suas produções poéticas fazem intersecções entre arte, ativismo e os feminismos, elementos que se interpelam e se multiplicam na Web, provocando deslocamentos e desajustes nas amarras sociais que subjugam as subjetividades das mulheres. De-

24 Disponivel em: <http://arvidabystrom.se/>. sobediência aos padrões sociais estabelecidos de feminilidade são características comuns e usuais entre as digifeministas e, justamente por isso, as artistas citadas já tiveram suas contas suspensas no Instagram e no Facebook, curiosamente, empresas do mesmo grupo empresarial.

As redes sociais são conhecidas por censurarem imagens interpretadas como não apropriadas para serem vistas em suas plataformas e, frequentemente, surgem notícias de injustiças nos julgamentos anônimos, revelando ca-

25 Disponivel em: <https://www.instagram.com/arvidabystrom/>. 
sos de racismo, sexismo e machismo explícito por parte dos avaliadores, problema que também denuncia a falsa neutralidade das mídias sociais. Em realidade, conforme vamos acumulando experiências nos ambientes digitais, o jogo das relações de poder também vai ficando mais evidente e as digifeministas sabem que seus conteúdos são avaliados por subjetividades masculinas, detentoras do poder de julgamento, censura e aplicação de sanções punitivas nas mídias interativas.

Em uma espécie de posicionamento: "não temos nada a perder", as artistas digifeministas subvertem normas e desafiam a linha tênue entre aquilo que é, ou não, publicável. Fazem dos ciberespaços pontes para a desconstrução das relações de saber e poder normalizados e lugares para o exercício de uma agência coletiva crítica sobre as construções culturais, questionando silêncios, provocando rupturas, borrando as fronteiras de gênero, do sexo e dos desejos velados, abrindo rotas de fuga e descontinuidades nas narrativas hegemônicas.

As digifeministas parecem que ainda não se livraram da pergunta sempre presente nas inquietações feministas: afinal, "o que é ser mulher?" Seguimos com esse questionamento e o mito irônico criado por Haraway (1991) continua ativo na internet e cada vez mais mulheres preferem ser ciborgs a deusas.

\section{Desconectando...}

A sociedade hiperconectada gerou uma ilusão de solidariedade e diversidade das representações identitárias, mas, como disse ByungChul Han (2013, p. 12), é o inferno do igual. As digifeministas têm colaborado para romper com esse pacto de monotonia e executam um contínuo contra-ataque às sociedades normativas e suas visualidades padronizadas. Ainda que suas atividades se deem no âmbito micropolítico - ao contrário das previsões das ciber- feministas do final do século passado -, o impacto de suas ações segue sendo um exercício importante para a transformação das relações de poder e a visibilidade de práticas alternativas da subjetividade feminina.

Entretanto, os ciberespaços ainda não são lugares acolhedores para as mulheres. Nem para a comunidade negra ou os sujeitos não heteronormativos. Todas essas pessoas enfrentam as mesmas dificuldades e discriminações, tanto on-line como off-line. A diferença é que, nas plataformas interativas, muitas identidades parecem se sentir mais confortáveis pra insultar, agredir e destilar discursos de ódio contra determinados grupos sociais.

Assim, como produto de nossas criações, a internet não está imune às relações estabelecidas dentro dos marcos sociais, econômicos, políticos e culturais, que continuam a alimentar comportamentos sexistas e racistas. Portanto, as ações das digifeministas encontram resistências, obstáculos e geram reações muitas vezes pouco amistosas com seus ideais e atos políticos. Todavia, se a internet parece estar atravessada pelas lógicas regulatórias de gestão da identidade, dos corpos e das subjetividades, ao mesmo tempo, oferece ferramentas com potencial político e de resistência crítica para desestabilizar os regimes de poder, além de oferecer possibilidades para a ativação de novos processos de subjetivação dissidentes.

As ações das digifeministas interpelam e testam os limites da política sexual contemporânea com o objetivo de apontar aquilo que as normas excluem, inviabilizam ou silenciam. As artistas, em especial, exploram os corpos em suas potências e devires, reinventando possibilidades de criar afetos e prazeres resistentes às classificações normativas, que ensinam empiricamente, e por meio da repetição, como as mulheres devem ser.

Desde a década de 1990, as feministas subvertem usos e constroem novos sentidos por 
meio das ferramentas digitais. Hoje, a nova geração de feministas praticam a crítica política desde a experiência pessoal e suas ações e narrativas repercutem coletivamente por meio das redes sociais. Usam os espaços digitais para o ativismo e a mobilização feminista; para expor e divulgar trabalhos artísticos; para a visibilização e denúncia de condutas violentas ou abusivas; para a formação profissional no desenvolvimento de tecnologias e softwares; para o intercâmbio de conhecimentos e saberes que ultrapassam as fronteiras físicas. Portanto, as ferramentas tecnológicas também têm proporcionado formas de empoderamento e agência política feminina, através de produções artísticas e histórias de resistência e transformação das relações de poder e saber.

Com as experiências passadas, aprendemos que as tecnologias não facilitarão a emancipação da mulher e, provavelmente, nem sequer uma nova representação feminina. Para isso ocorrer são necessárias mais ações promovedoras de olhares críticos diante das desigualdades e, talvez, um atrevimento maior nas propostas de confronto, para deslumbrarmos possibilidades de mudanças nas maneiras como construímos as representações identitá-

\section{Referências}

ABREU, C. de. Géneros y sexualidades no heteronormativas en las redes sociales digitales. 2014. $393 \mathrm{f}$. Tese (Doutorado em "Artes y Educación") - Facultad de Bellas Artes, Universitad de Barcelona, Barcelona, España, 2014.

BUTLER, J. Gender trouble: feminism and the subversion of identity. New York : Routledge, 1990.

FUSS, D. Inside/out: lesbian theories, gay theories. New York: Routledge, 1991.

HALPERIN, D. Saint Foucault: towards a gay hagiography. New York: Oxford University Press. 1995.

HAN, Byung-Chul. La sociedad de la transparencia. rias, libertando-nos dos ideais de dominação e coisificação da mulher.

Há um caminho longo a ser percorrido. Talvez, as digifeministas precisarão "ver mais" e ver de forma distinta os contextos sociais, para abrir espaços e condições para a transformação política do "olhar", facilitando outras formas de narrativa e de representações femininas que criem ruídos e desconfortos no marasmo confortavelmente instalado nas mídias interativas. Mas, o mais importante, é continuar o exercício de questionar as próprias condições de possibilidades do olhar, ou seja, o tipo de olhar que exclui ou limita o surgimento de práticas alternativas de subjetividades não normativas.

Nesse questionamento contínuo dos "olhares", a pergunta já não é somente "o que vemos", mas como vemos e por que vemos assim. Não se trata apenas de ampliar o alcance do olhar, mas, acima de tudo, provocar ruídos, tensões, interferir nas premissas dos discursos de poder e descobrir as potencialidades dos entre-olhares, gerados pelos encontros, as fricções, a articulação, o conflito, o confronto e, principalmente, as afinidades pelos ideais feministas na internet.

Tradução de Raúl Gabás. Barcelona: Herder, 2013.

HARAWAY, D. A Cyborg Manifesto: Science, Technology, and Socialist-Feminism in the Late Twentieth Century. In: HARAWAY, D. Simians, cyborgs and women: the reinvention of nature. New York: Routledge, 1991. p. 149-181.

KENDALL, L. Hanging out in the virtual pub: masculinities and relationships online. Berkeley: University of California Press, 2002.

LARA; RANGEL, et al. \#MeuAmigoSecreto: feminismo além das redes. Rio de Janeiro: Edições de Janeiro, 2016. 
de LAURETIS, T. Queer Theory: Lesbian and Gay Sexualities. Differences: a Journal of Feminist Cultural Studies, 3, n. 2, 1991. p. iii-xviii.

MARTÍNEZ-COLLADO, A. Cyberfeminismo: tecnología, subjetividad y deseo. In: ALIAGA, J. V. Miradas sobre la sexualidad en el arte y la literatura del siglo $X X$ en Francia y España. València: Servei de Publicacions de la Universitat de València, 2001. p. 217-228.

MARTíneZ-COllado, A. Tendenci@as. Perspectivas feministas en el arte actual. 2. ed. Murcia: Centro de Estudios de Arte Contemporáneo, 2005.

PLANT, S. Ceros + Unos, Mujeres digitales + la nueva tecnocultura. Barcelona: Ediciones Destinos, 1998.

SEDGWICK, E. K. Epistemology of the closet. Berkeley: University of California Press, 1990.

STOFENMACHER, I. Ciberfeminismo: la feminización de la red. Teknokultura, Puerto Rico, v. 2, ago. 2002.

STONE, S. Will the Real Body Please Stand Up? In: BENEDIKT, M. Cyberspace. Cambridge: First Steps (MIT Press), 1991. p. 81-118.
SUNDÉN, J. Material virtualities: approaching online textual embodiment. New York: Peter Lang ed., 2003.

TURKLE, S. Life on the screen: identity in the age of the Internet. New York: Simon \& Schuster, 1995. ISBN: 0684803534.

VAN ZOONEN, L. Gendering the Internet. Claims, controversies and cultures. European Journal of Communication, v. 17, p. 5-23, 2002.

WAJCMAN, J. El tecnofeminismo. Madrid: Cátedra, 2006. (Colección Feminismos).

WARNER, M. Fear of a queer planet: queer politics and social theory. Minneapolis: University of Minnesota Press, 1993. ZAFRA, R. Ciberfeminismo. Bases y propuestas en un mundo global. Mujer y Cultura Visual, s/n, 2004. Disponível em: <http://hdl.handle. net/11441/26536>. Acesso em: 28 nov. 2016.

ZAFRA, R. Netianas. N(h)acer mujer en Internet. Madrid: Lengua de Trapo, 2005. (Colección Desórdenes).

Recebido em: 20.12.2016

Aprovado em: 03.03.2017

Carla de Abreu é Professora na Faculdade de Artes Visuais, Universidade Federal de Goiás (FAV/UFG). Doutora em Artes Visuales y Educación (Universidade de Barcelona - UB, Espanha). Membro dos grupos de pesquisa: Cultura Visual e Educação (UFG/CNPq) e Transviações: Educação e Visualidade (UnB/CNPq). e-mail: carlaluzia@gmail.com

Universidade Federal de Goiás (UFG). Campus Samambaia. Caixa Postal 131 - 74.001-970 - Goiânia (GO) - Brasil. Secretaria: Telefax (62) 3521-1440, 